\title{
Ocorrência de Leishmania spp. em felinos do município de Araçatuba, SP
}

\author{
Occurrence de Leishmania spp. in domestic cats from Araçatuba, SP
}

Katia Denise Saraiva Bresciani ${ }^{1 *}$; Ana Claudia Marques Serrano ${ }^{1}$; Lucas Vinicius Shigaki de Matos ${ }^{1}$; Elisa San Martin Mouriz Savani²; Sandra Regina Nicoletti D’Auria ${ }^{2}$; Silvia Helena Venturoli Perri ${ }^{1}$; Fabio Luiz Bonello ${ }^{1}$; Willian Marinho Dourado Coelho ${ }^{3}$; Carolina Godoi Aoki ${ }^{1}$; Alvimar José da Costa ${ }^{4}$

\author{
${ }^{1}$ Departamento de Apoio, Produção e Saúde Animal, Faculdade de Odontologia de Araçatuba - FOA, \\ Universidade Estadual Paulista - UNESP \\ ${ }^{2}$ Laboratório de Zoonoses e Doenças Transmitidas por Vetores do Município de São Paulo, \\ Centro de Controle de Zoonoses de São Paulo - CCZ \\ ${ }^{3}$ Departamento de Medicina Veterinária Preventiva, Faculdade de Ciências Agrárias e Veterinárias - FCAV, \\ Universidade Estadual Paulista - UNESP \\ ${ }^{4}$ Centro de Pesquisas em Sanidade Animal - CPPAR, Universidade Estadual Paulista - UNESP
}

Recebido em 5 de Janeiro de 2010

Aceito em 29 de Janerio de 2010

\section{Resumo}

Este trabalho teve como objetivo comparar a ocorrência de Leishmania spp. em gatos por dois métodos (citológico e sorológico), bem como associar a ocorrência deste protozoário com as variáveis sexo, idade e raça. Amostras séricas de 283 felinos domésticos foram testadas pela Reação de Imunofluorescência Indireta (RIFI), e o exame parasitológico direto de linfonodos também foi realizado para a verificação da positividade para Leishmania spp. Ocorrência de 0,7\% (2/283) foi observada nos felinos examinados, por meio de imprint de linfonodos e nenhum animal apresentou títulos de anticorpos para Leishmania spp. As duas fêmeas positivas eram sem raça definida, sendo uma jovem e outra adulta. Por meio dos resultados obtidos, não foi constatada diferença estatisticamente significante em relaçáo às variáveis sexo, raça e idade nos gatos desta pesquisa ( $\mathrm{p}>0,05$ ). Ocorrência de Leishmania spp. nos gatos deste estudo foi baixa. Devido a esta baixa incidência sugere-se que estes não assumem importância epidemiológica na área do estudo.

Palavras-chave: Leishmania spp., gato, sorologia, linfonodos, imprint.

\begin{abstract}
This study had the purpose to compare the occurrence of Leishmania spp. in felines through two methods (cytological and serological), as well as to associate the occurrence of this protozoan with the sex, age and breed variables. Serum samples from 283 domestic felines were processed by means of Indirect Immunofluorescence Reaction (IIR), and the direct parasitological test for linfonodes was also carried out in order to verify positivity for Leishmania spp. Occurrence of $0.7 \%(2 / 283)$ was observed in the tested felines by means of linfonode imprinting and no animal showed title of antibodies for Leishmania spp. The two positive females were mongrel, a young female and an adult female feline. From the obtained results, no statistically significant difference was observed as regards the sex, breed and age variables in this research ( $\mathrm{p}>0.05$ ). Occurrence of Leishmania spp. in the cats of this study was low. Such low incidence suggests that these hosts has no epidemiological relevance in the study area.
\end{abstract}

Keywords: Leishmania spp., cat, serology, lymphonodes, imprint.

\footnotetext{
*Autor para correspondência: Katia Denise Saraiva Bresciani

Departamento de Apoio, Produção e Saúde Animal,

Faculdade de Odontologia de Araçatuba - FOA,

Universidade do Estado de São Paulo - UNESP, Rua Clóvis Pestana, 793,

CEP 16050-680, Araçatuba - SP, Brasil;

e-mail: bresciani@fmva.unesp.br
} 
Autores em diversos países, como França (PRATLONG et al., 2004); Itália (POLI et al., 2002; PENNISI et al., 2004); Suíça (RÜFENACHT et al., 2005); Espanha (SOLANO-GALLEGO et al., 2007) e Brasil (SAVANI et al., 2004; SOUZA et al., 2005; DANTAS-TORRES et al., 2006; ROSSI, 2007; SILVA et al., 2008; SERRANO et al., 2008), observaram a ocorrência da infecção por Leishmania em felinos.

Este trabalho teve como objetivo avaliar a ocorrência de dois métodos (citológico e sorológico) no diagnóstico de Leishmania em gatos, bem como verificar a associaçáo desses resultados com as variáveis sexo, idade e raça.

Um total de 283 felinos, domiciliados, foram encaminhados por seus proprietários ao Centro de Controle de Zoonoses (CCZ) do Município de Araçatuba, São Paulo. A idade foi estimada por meio da análise da arcada dentária. Um banco de dados foi elaborado, utilizando-se as variáveis sexo, raça e idade em associação aos respectivos resultados de cada felino.

Os animais foram eutanasiados segundo procedimentos aprovados pela Comissão de Ética em Experimentação Animal da Faculdade de Odontologia de Araçatuba (FOA) UNESP (protocolo $\mathrm{n}^{\circ}$. 2007-003276).

Para a Reação de Imunofluorescência Indireta (RIFI), empregou-se como antígeno formas promastigotas de Leishmania (L.) chagasi, sendo considerado reagente o título igual ou acima de 40.

Fragmentos de linfonodos poplíteos foram processados por meio de impressão (imprint) em lâminas de microscopia em duplicata, coradas com o corante Panótico Rápido (Hematocor, Biolog) e observadas em microscopia de luz, com aumento de $1.000 \times$, analisando-se 300 campos.

Para análise estatística foi utilizado o teste exato de Fisher para verificar existência de associação entre as variáveis estudadas e o resultado do imprint. O nível de significância adotado foi de 5\%. A análise estatística foi realizada pelo sistema computacional SAS.

Na Tabela 1, observou-se $0,7 \%(2 / 283)$ de positividade nos felinos examinados, por meio de imprint de linfonodos e nenhum animal apresentou sorologia positiva para Leishmania spp. As duas fêmeas positivas ao exame parasitológico eram sem raça definida, sendo uma jovem e outra adulta.
Tendo em vista os resultados obtidos, não foi constatada diferença estatisticamente significante em relação às variáveis sexo, raça e idade nos gatos deste estudo $(p>0,05)$.

No presente trabalho, um dos gatos em que foi detectada Leishmania apresentou alterações dermatológicas. Rossi (2007) não constatou quaisquer sinais clínicos em felinos positivos para o protozoário.

Neste trabalho, foi observada ocorrência de 0,7\% (2/283) para Leishmania pelo exame de imprints de linfonodos. Também Rossi (2007), em Araçatuba, verificou 4\% (8/200) de positividade para Leishmania por meio da pesquisa direta de formas amastigotas de Leishmania em punçóes aspirativas de linfonodos, medula óssea, baço e fígado.

Os gatos do presente estudo foram negativos pela RIFI (Reação de Imunofluorescência Indireta) para Leishmania. Poli (2002), na Itália, observou $0,9 \%(1 / 110)$ de ocorrência de anticorpos contra Leishmania pela RIFI. Esse resultado é semelhante ao de Rossi (2007), em Araçatuba, o qual verificou 0,5\% (1/200) de sororreagentes pela mesma técnica.

Em caso de felino sorologicamente negativo pela RIFI e ELISA e positivo na PCR (Polimerase Chain Reaction) para Leishmania, a resposta humoral contra esse protozoário foi possivelmente baixa. Assim, os autores evidenciam a necessidade de mais pesquisas sobre a resposta imune diferenciada dos gatos frente ao parasito e à investigação dos mesmos como reservatórios da enfermidade (SERRANO et al., 2008).

As análises apresentaram resultados positivos, ainda que estatisticamente não significativos perante a amostra utilizada. Esses animais examinados eram domiciliados, e este fato é relevante sob o ponto de vista de saúde pública, no aspecto de adoção de medidas profiláticas e de controle na disseminação da doença.

A ocorrência de infecção por Leishmania foi baixa nos felinos deste estudo. Devido a esta pequena incidência sugere-se que estes hospedeiros não assumem importância epidemiológica na área do estudo.

Agradecemos à Silvana Rodrigues Alves pelo apoio na realização deste trabalho.

Tabela 1. Ocorrência de Leishmania spp. em felinos domiciliados do Município de Araçatuba, por meio da Técnica de Reação de Imunofluorescência Indireta (RIFI) e imprint de linfonodos.

\begin{tabular}{|c|c|c|c|c|c|c|c|c|}
\hline \multirow{3}{*}{ Variável } & \multirow{3}{*}{ Categoria } & \multicolumn{6}{|c|}{ Imprint de linfonodos } & \multirow{3}{*}{$\mathbf{p}$} \\
\hline & & \multicolumn{2}{|c|}{ Positivo } & \multicolumn{2}{|c|}{ Negativo } & \multicolumn{2}{|c|}{ Total } & \\
\hline & & $\mathbf{N}$ & $\%$ & $\mathbf{N}$ & $\%$ & $\mathbf{N}$ & $\%$ & \\
\hline \multirow{2}{*}{ Raça } & Siamês & 0 & 0,0 & 28 & 100,0 & 28 & 100,0 & \multirow{2}{*}{1,0000} \\
\hline & SRD & 2 & 0,8 & 253 & 99,2 & 255 & 100,0 & \\
\hline \multirow{2}{*}{ Sexo } & Macho & 0 & 0,0 & 118 & 100,0 & 118 & 100,0 & \multirow{2}{*}{0,5121} \\
\hline & Fêmea & 2 & 1,2 & 163 & 98,8 & 165 & 100,0 & \\
\hline \multirow{4}{*}{ Idade } & Jovem & 1 & 0,7 & 133 & 99,3 & 134 & 100,0 & \multirow{4}{*}{1,0000} \\
\hline & Adulto-jovem & 0 & 0,0 & 2 & 100,0 & 2 & 100,0 & \\
\hline & Adulto & 1 & 0,7 & 138 & 99,3 & 139 & 100,0 & \\
\hline & Idoso & 0 & 0,0 & 8 & 100,0 & 8 & 100,0 & \\
\hline RIFI & Negativo & 2 & 0,7 & 281 & 99,3 & 283 & 100,0 & - \\
\hline
\end{tabular}




\section{Referências}

DANTAS-TORRES, F. et al. Leishmaniose felina: revisão de literatura. Clínica Veterinária, n. 61, p. 32-40, 2006.

PENNISI, M. G. et al. Case report of leishmaniasis in four cats. Veterinary Research Communications, v. 28, p. 363-366, 2004.

POLI, A. et al. Feline leishmaniosis due to Leishmania infantum in Italy. Veterinary Parasitology, v. 106, n. 3, p. 181-191, 2002.

PRATLONG, F. et al. Isoenzymatic analysis of 712 strains of Leishmania infantum in the south of France and relationship of enzymatic polymorphism to clinical and epidemiological features. Journal Clinical Microbiology, v. 42, n. 9, p. 4077-4082, 2004.

ROSSI, C. N. Ocorrência de Leishmania sp em gatos do município de Araçatuba-São Paulo - Brasil. 2007. 87 f. Dissertação (Mestrado) Universidade Estadual Paulista, Jaboticabal, 2007.

RÜFENACHT, S. et al. Two cases of feline leishmaniosis in Switzerland. Veterinary Record, v. 156, n. 17, p. 542-545, 2005.
SAVANI, E. S. M. M. et al. The first Record in the Américas an autochthonous case of Leishmania (Leishmania) infantum chagasi in a domestic cat (Felix catus) from Cotia Couty, São Paulo State, Brazil. Veterinary Parasitology, v. 120, n. 3, p. 229-233, 2004.

SERRANO, A. C. M. et al. Leishmaniose em felino na zona urbana de Araçatuba - SP - relato de caso. Clínica Veterinária, n. 76, p. 36-40, 2008.

SILVA, M. A. et al. the first record of american visceral leishmaniasis in domestic cats from Rio de Janeiro, Brazil. Acta Tropica, v. 105, n. 1, p. 92-94, 2008.

SOLANO-GALLEGO, L. et al. Cross-sectional serosurvey of feline leishmaniasis in ecoregions around the Northwestern Mediterranean. American Journal Tropical Medicine Hygiene, v. 76, n. 4, p. 676-680, 2007.

SOUZA, A. L. et al. Feline leishmaniasis due to Leishmania (Leishmania) amazonensis in Mato Grosso do Sul State, Brazil. Veterinary Parasitology, v. 128, n. $1-2$, p. $41-45,2005$. 